\section{MAR SALGADO}

Ao escrever no seu livro "Mensagem" os geniais versos "Ó mar salgado, quanto do teu sal são lágrimas de Portugal”, estava Fernando Pessoa longe de pensar que, tantas décadas depois, as agruras da epopeia marítima e da secular relação dos Portugueses com o mar viriam a conhecer um novo e problemático desenvolvimento: a nossa relação com o sal propriamente dito.

Desde tempos imemoriais usado como uma importante forma de conservação de alimentos, o seu consumo começou a ser relacionado há algumas décadas com o aparecimento de algumas doenças crónicas, nomeadamente a hipertensão arterial e a doença cardiovascular, sendo hoje bem estabelecida essa relação, estando também razoavelmente definidos os limites para o seu consumo saudável. No entanto, pese embora a esmagadora evidência científica, persiste uma tremenda dificuldade em reduzir o seu consumo para níveis considerados satisfatórios. O preço a pagar por este excesso é enorme: de acordo com os dados mais recentes disponíveis no Global Burden of Disease, as doenças cardiovasculares e, em particular, o acidente vascular cerebral, são a principal causa de morte e de peso da doença no nosso país. Ora é bem conhecida a relação entre o consumo de sal e a doença cardiovascular, nomeadamente pela decisiva influência que este tem na hipertensão arterial, cuja prevalência em Portugal é altíssima.
Neste contexto, são publicados dois artigos no presente número da Acta Portuguesa de Nutrição que abordam esta temática. O primeiro, de Pinheiro e colaboradores, mostra que na cidade de Porto Alegre, no Brasil, o consumo de sal por adolescentes é uma das principais desadequações de ingestão nutricional nesta população, atingindo quase $90 \%$ da amostra, revelando que este é um problema que se instala bem cedo no ciclo de vida. O segundo, por Mota e colaboradores, mostra-nos, numa revisão, que apesar de tudo é possível intervir, neste caso em cantinas, de forma a reduzir a quantidade de sal que é adicionada às refeições, através de vários tipos de abordagem, embora mostre igualmente que a evidência disponível é ainda insuficiente.

O caminho para a redução do consumo de sal é longo e está muito distante de um epílogo aceitável. Todas as medidas serão poucas para atenuar este problema e, tal como já demonstrado noutros países e contextos, a intervenção política será determinante.

Essa intervenção só será eficaz, todavia, se baseada na melhor evidência científica disponível. É a publicação desse tipo de evidência que justifica e dá alento para a prossecução do trabalho da Acta Portuguesa de Nutrição e de todos os que com ela colaboram.

\section{Nuno Borges}

Diretor da Acta Portuguesa de Nutrição 